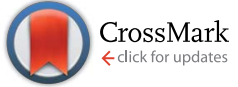

Cite this: J. Mater. Chem. A, 2015, 3, 4420

Received 28th October 2014

Accepted 8th December 2014

DOI: $10.1039 / \mathrm{c} 4 \mathrm{ta0} 5774 \mathrm{k}$

www.rsc.org/MaterialsA

\title{
The combination of a new organic $D-\pi-A$ dye with different organic hole-transport materials for efficient solid-state dye-sensitized solar cells $\uparrow$
}

\author{
Peng Liu, ${ }^{\mathrm{a}}$ Bo Xu, ${ }^{\mathrm{b}}$ Karl Martin Karlsson, ${ }^{\mathrm{a}}$ Jinbao Zhang, ${ }^{\mathrm{c}}$ Nick Vlachopoulos, \\ Gerrit Boschloo, ${ }^{C}$ Licheng Sun ${ }^{\mathrm{b}}$ and Lars Kloo*a
}

\begin{abstract}
A new organic donor- $\pi$-acceptor sensitizer MKA253 has been applied for highly efficient solid-state dyesensitized solar cells (ssDSSCs). Using 2,2',7,7'-tetrakis( $N, N$-di-p-methoxyphenyl-amine)9, $9^{\prime}$-spirobifluorene (Spiro-OMeTAD) as the hole transport material (HTM), an excellent power conversion efficiency of $6.1 \%$ was recorded together with a high short-circuit current of $12.4 \mathrm{~mA} \mathrm{~cm}{ }^{-2}$ under standard AM $1.5 \mathrm{G}$ illumination $\left(100 \mathrm{~mW} \mathrm{~cm}^{-2}\right.$ ). Different combinations of dyes and HTMs have also been investigated in the sSDSSC device. The results showed that small molecule HTM based devices suffer from comparably high electron recombination losses, thus causing low open-circuit voltage. In addition, photo-induced absorption (PIA) spectroscopy showed that the small-molecule HTMs lead to more efficient dye regeneration in comparison with Spiro-OMeTAD, despite a lower thermodynamic driving force. The results of this study also show that optimized energy levels for the dye-HTMs could be a vital factor for highly efficient ssDSSCs.
\end{abstract}

\section{Introduction}

Dye sensitized solar cells (DSSCs) represent promising renewable energy conversion devices because of their low fabrication costs, environmentally friendly features, and excellent conversion efficiency. As originally reported in 1991, by O'Regan and Grätzel, ${ }^{1}$ incident light is absorbed by a dye that is chemically attached to a mesoporous semiconductor substrate, typically consisting of anatase titanium dioxide. Upon light-induced excitation, the dye molecules inject electrons into the conduction band of titanium dioxide, leaving the holes in the dye molecules. The electrolyte redox couples or, alternatively, a hole transport material (HTM) subsequently transport the holes to the counter electrodes, thus regenerating the dye molecules. For decades, many scientists and researchers have made significant effort to make highly efficient DSSCs. ${ }^{2-4}$ The DSSCs based on liquid electrolytes have achieved conversion efficiencies of over $10 \%$ based on ruthenium dyes, ${ }^{5}$ and metal-free organic dyes. ${ }^{\mathbf{4}, \mathbf{6}, 7}$ Recently, the best performing DSSCs exhibit a power conversion

${ }^{a}$ Applied Physical Chemistry, Center of Molecular Devices, Department of Chemistry, School of Chemical Science and Engineering, KTH-Royal Institute of Technology, SE-10044 Stockholm, Sweden. E-mail: Lakloo@kth.se

${ }^{b}$ Organic Chemistry, Center of Molecular Devices, Department of Chemistry, School of Chemical Science and Engineering, KTH-Royal Institute of Technology, SE-10044 Stockholm, Sweden

${ }^{c}$ Department of Chemistry-Ångstrom Laboratory, Physical Chemistry, Uppsala University, SE-75120 Uppsala, Sweden

$\dagger$ Electronic supplementary information (ESI) available. See DOI: $10.1039 / \mathrm{c} 4 \mathrm{ta} 05774 \mathrm{k}$ efficiency of $13 \%$ containing a porphyrin dye and an electrolyte based on a cobalt redox shuttle, ${ }^{8}$ providing an efficient mechanism for the hole transport. However, the liquid cells suffer from potential leakage and corrosion problems associated with the volatile and corrosive nature of the liquid electrolyte. In an effort to address these issues, solid-state HTMs have been developed to replace the liquid electrolyte by scientists. ${ }^{9-11}$ In 2011, ssDSSCs with a record $7.2 \%$ efficiency were reported by Grätzel and coworkers, and the cells were based on the HTM 2,2',7,7'-tetrakis( $N, N$-di-p-methoxyphenyl-amine)9, $9^{\prime}$-spirobifluorene (SpiroOMeTAD) employing a cobalt complex dopant and customsynthesized dyes. ${ }^{\mathbf{1 2}}$ Lately, In Chung et al. have reported the p-type inorganic semiconductor $\mathrm{CsSnI}_{3-x} \mathrm{~F}_{x}$ as a HTM improving the power conversion efficiencies up to $10.2 \% .^{13}$ Recently, solidstate perovskite solar cells with more than $15 \%$ power conversion efficiency have drawn lots of attention. ${ }^{\mathbf{1 4 - 1 6}}$

Currently, insufficient pore filling of the HTM into the relatively thick mesoporous titanium dioxide film has limited the ssDSSC performance. Due to the short diffusion length and incomplete pore filling, the ssDSSCs are consequently limited to very thin semiconductor substrate films. ${ }^{17-19}$ Therefore, dyes with a wide absorption range and high molar extinction coefficients are necessary in order to achieve a sufficient light-harvesting efficiency for high-performing solar cells.. ${ }^{\mathbf{2 0 1}}$ The organic donor- $\pi$-acceptor $(\mathrm{D}-\pi-\mathrm{A})$ dyes have drawn significant attention because of their high light-harvesting ability and low raw material cost. ${ }^{22-24}$ Typically, the donor part is a unit that is readily excited by incoming light, the $\pi$ part is the linker consisting of a conjugated system, and finally the acceptor part can 


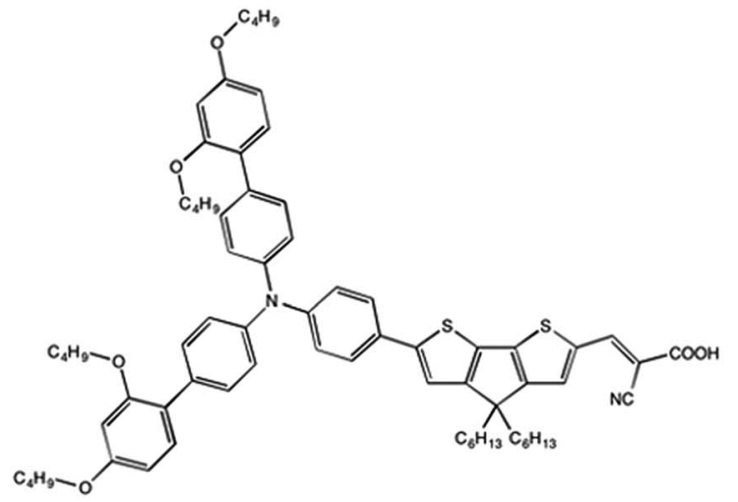

(a)

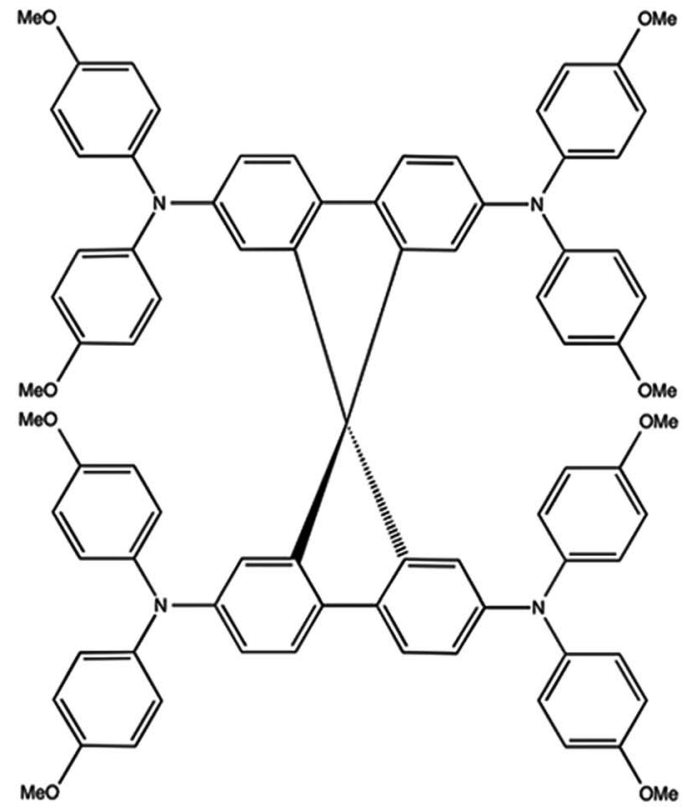

(c)

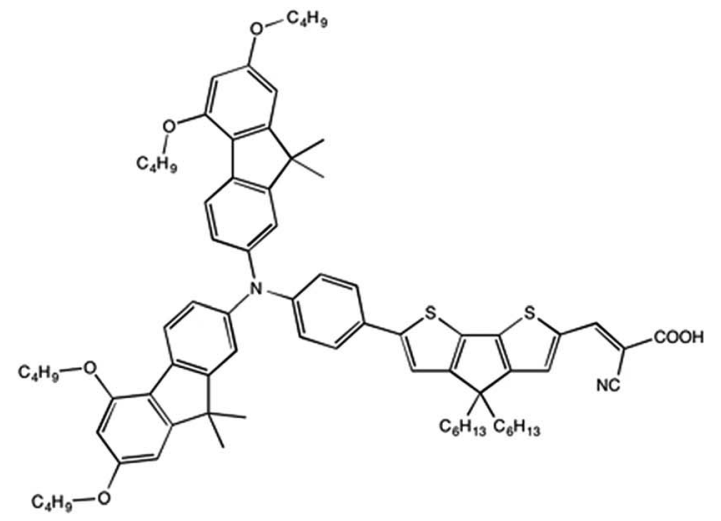

(b)

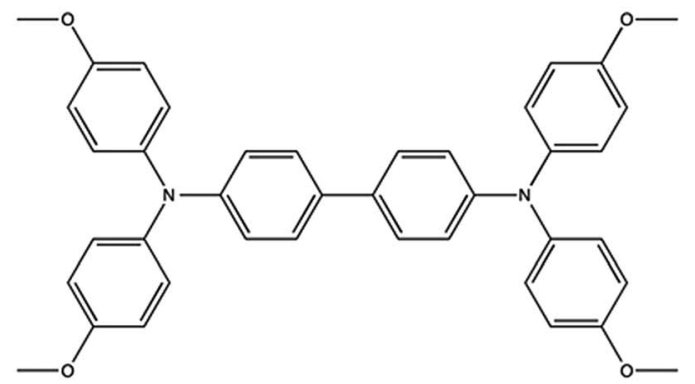

(d)

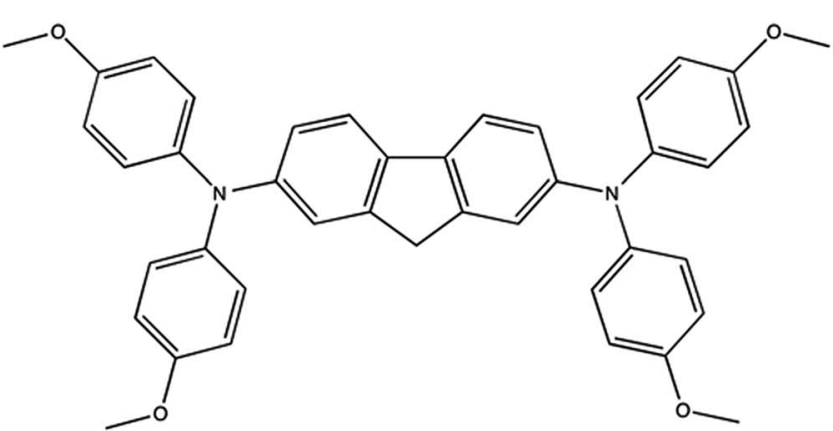

(e)

Fig. 1 Molecular structures of the different sensitizers (a) LEG4, (b) MKA253, and hole-transport materials: (c) Spiro-OMeTAD, (d) X1, and (e) X11.

act as an electron-withdrawing unit and an anchoring site to the substrate at the same time. It was previously reported that organic dyes based on a triphenylamine (TPA) based donor part are excellent for ssDSSCs, due to their good electron-donating ability and fast charge transfer at the dye-HTM interface. ${ }^{23,25}$ Thus, these organic dyes allow thinner device designs and promising photovoltaic performance.

Hole-transport materials have played a significant role in ssDSSCs. Spiro-OMeTAD, because of its good solubility in common solvents and accessibility (in spite of its high cost), has become a well-known HTM used in ssDSSCs. ${ }^{12,26,27}$ However, due to the disadvantages of high cost, low conductivity and relatively poor infiltration into the metal-oxide film, much effort has been made to find alternatives to replace Spiro-OMeTAD. ${ }^{28-31}$ Recently, Lei, Xu, Sun, Hagfeldt and co-workers used a small-molecule hole-transport material (MeO-TPD) to obtain $4.8 \%$ conversion efficiency after a 30 min light-soaking procedure. ${ }^{32}$ Eunkyong Kim and his co-workers introduced in situ solid state polymerization of conducting polymers for highly efficient ssDSSCs. ${ }^{33} \mathrm{Xu}$, Tian, Hagfeldt and Sun developed a triphenylamine-based oligomer hole-transport material introduced into ssDSSCs and obtained $5.8 \%$ conversion efficiency, ${ }^{34}$ and they lately improved the efficiency up to $6.0 \%$ by using carbazole-based HTMs under standard AM 1.5 solar light irradiation..$^{35}$ Zhang, Vlachopoulos and co-workers applied a photoelectrochemical polymerization (PEP) method in order to generate conducting polymers as HTMs and obtained high efficiencies of up to $5.6 \% .^{36,37}$ Recently, Grätzel and co-workers reported a new dye with a fluorene donor for liquid type DSSCs and obtained a high $J_{\mathrm{sc}}$ of $16.2 \mathrm{~mA} \mathrm{~cm} \mathrm{~cm}^{-2} \cdot{ }^{38}$ In this work, we report a new organic dye MKA253 applied to 
ssDSSCs, together with the effects of a selection of dye-HTM combinations on the power conversion efficiency. The structures of the materials studied in this work are presented in Fig. 1.

\section{Experimental section}

\subsection{Chemicals used}

All chemicals were purchased from Sigma-Aldrich unless otherwise indicated. The company Dyenamo AB supplied the dye LEG4. ${ }^{39}$ The synthesis of X1 follows the method described in ref. 32. More synthesis details can be found in the ESI. $\dagger$

\subsection{Device fabrication}

Fluorine-doped tin dioxide (FTO) substrates were dipped into a $\mathrm{Zn}-\mathrm{HCl}$ solution (zinc powder and $2 \mathrm{M}$ hydrochloric acid) for the etching process in order to form the desired electrode pattern. After that step, the substrates were cleaned in an ultrasonic bath in the following order: deionized water $(15 \mathrm{~min})$, acetone (30 $\mathrm{min})$, and ethanol (30 min). A spray pyrolysis deposition (SPD) technique was applied to obtain a compact layer of $\mathrm{TiO}_{2}$ as a blocking layer on top of the FTO substrate. The solution used in the SPD process was $0.2 \mathrm{M}$ Ti-isopropoxide and $2 \mathrm{M}$ acetylacetone in isopropanol, and a 10-spray cycle was used as the standard procedure. In order to generate the nano-porous $\mathrm{TiO}_{2}$ film, a $\mathrm{TiO}_{2}$ paste (Dyesol DSL 18NR-T) mixed with terpineol ( $2: 1$ mass ratio) was deposited on the compact layer of $\mathrm{TiO}_{2}$ using a screen-printing method. After sintering on a hotplate at $500{ }^{\circ} \mathrm{C}$ for $30 \mathrm{~min}$ and cooling to room temperature, the substrate was immersed into a solution of $0.2 \mathrm{M}$ aqueous $\mathrm{TiCl}_{4}$ at $70{ }^{\circ} \mathrm{C}$ for $30 \mathrm{~min}$. Then, the substrates were rinsed with deionized water and ethanol and annealed on a hotplate at $500{ }^{\circ} \mathrm{C}$ for $30 \mathrm{~min}$. After being cooled to $90{ }^{\circ} \mathrm{C}$, the hot $\mathrm{TiO}_{2}$ film was immersed into a dye bath for $18 \mathrm{~h}$. The dye bath solution in this work was $0.2 \mathrm{mM}$ of organic dye (LEG4 or MKA253) in a mixed solvent of tert-butanol and acetonitrile $(1: 1)$. After the sensitization, the electrodes were rinsed with ethanol and dried in an $\mathrm{N}_{2}$ gas flow. The surfaces of the dried substrates were covered by an HTM solution containing additives for $30 \mathrm{~s}$ and then spin-coated for $30 \mathrm{~s}$ at $2000 \mathrm{rpm}$ to form a uniform HTM layer. Afterwards, the cells were left in air overnight in the dark and a $200 \mathrm{~nm}$ thick $\mathrm{Ag}$ layer was deposited on the top of the HTM layer by thermal evaporation in a vacuum chamber (Leica EM MED020).

\subsection{Device characterization}

Current-voltage characteristics of the ssDSSCs were studied under $100 \mathrm{~mW} \mathrm{~cm} \mathrm{~cm}^{-2}$ (AM 1.5) radiation using a Keithley Model 2400 source meter. The light source was calibrated by a certified reference solar cell (Fraunhofer ISE). A black mask with an aperture area of $0.126 \mathrm{~cm}^{2}$ was placed on the top of the cell during the measurements. Incident photo-to-current conversion efficiency (IPCE) spectra were recorded by a computercontrolled setup comprised of a xenon lamp (Spectral Products ASB-XE-175), a monochromator (Spectral Products CM110) and a Keithley multimeter (Model 2700), calibrated by a certified reference solar cell (Fraunhofer ISE). The electron lifetime data were recorded through monitoring photovoltaic transients at different light intensities by applying a small square-wave modulation to a base light intensity. The photovoltaic response was fitted using first-order kinetics in order to obtain the time constants. $^{3}$

\subsection{Photoinduced absorption spectroscopy}

The solar cell device samples used in photoinduced absorption (PIA) measurements were prepared as described above except for the Ag contact layer. PIA spectra were recorded on an in-lab constructed setup. ${ }^{40} \mathrm{~A} 20 \mathrm{~W}$ tungsten-halogen lamp, filtered up to $530 \mathrm{~nm}$, generated the white probe light. A square-wave modulated (on-off) green light source (Lasermate GML532-100FLE, $532 \mathrm{~nm}$ ) was used for excitation. The transmitted probe light was focused onto a monochromator and detected by a UV-enhanced silicon and germanium photodiode detector. $6.1 \mathrm{~mW} \mathrm{~cm} \mathrm{~cm}^{-2}$ light intensity and $9.3 \mathrm{~Hz}$ modulation frequency were used for the blue LED excitation.

\subsection{UV-Vis absorption measurement}

UV-Vis absorption measurement was performed using a Lambda 750 UV-Vis spectrophotometer. The signal from the $\mathrm{FTO} / \mathrm{TiO}_{2}$ substrate was used for calibration. The thickness of the $\mathrm{TiO}_{2}$ films studied was around $500 \mathrm{~nm}$.

\subsection{Conductivity measurement}

Glass substrates without a conductive layer were carefully cleaned. Remaining organic residues were removed by $10 \mathrm{~min}$ airbrushing. A thin layer of nanoporous $\mathrm{TiO}_{2}$ was coated onto the glass substrates by spin-coating using a diluted $\mathrm{TiO}_{2}$ paste (Dyesol DSL 18NR-T) with terpineol (1:3, mass ratio). The thickness of the film is $c a .500 \mathrm{~nm}$, as measured using a DekTak profilometer. The concentrations of the HTM solutions were the same as used for the photovoltaic devices. $J-V$ characteristics were recorded on a Keithley 2400 semiconductor characterization system. Measurements were carried out following the procedure described in a previously published paper. ${ }^{37}$

\section{Results and discussion}

\subsection{Materials characterization}

Fig. 2a shows the light absorbance spectra of the two dyes, LEG4 and MKA253, in ethanol solution and adsorbed onto the $\mathrm{TiO}_{2}$ film. Accordingly, MKA253 shows a broader light absorption range, up to $600 \mathrm{~nm}$, as compared to LEG4. The absorption maximum of LEG4 and MKA253 is $520 \mathrm{~nm}$ and $534 \mathrm{~nm}$ in ethanol solution, respectively, and $458 \mathrm{~nm}$ and $491 \mathrm{~nm}$ on the $\mathrm{TiO}_{2}$ film. A blue-shift is observed when the dyes are adsorbed onto the surface of the mesoporous $\mathrm{TiO}_{2}$ films. Previous studies have shown that a blue-shift of the absorption is found upon deprotonation of the terminal carboxylic group of the dye molecules. ${ }^{41,42} \mathrm{~A}$ much broader absorption range indicates better light-harvesting abilities of a specific dye, which is beneficial for obtaining highly efficient ssDSSCs. In order to make efficient ssDSSCs, one of the most basic requirements for a sensitizer and an HTM is that the HOMO energy level of the 


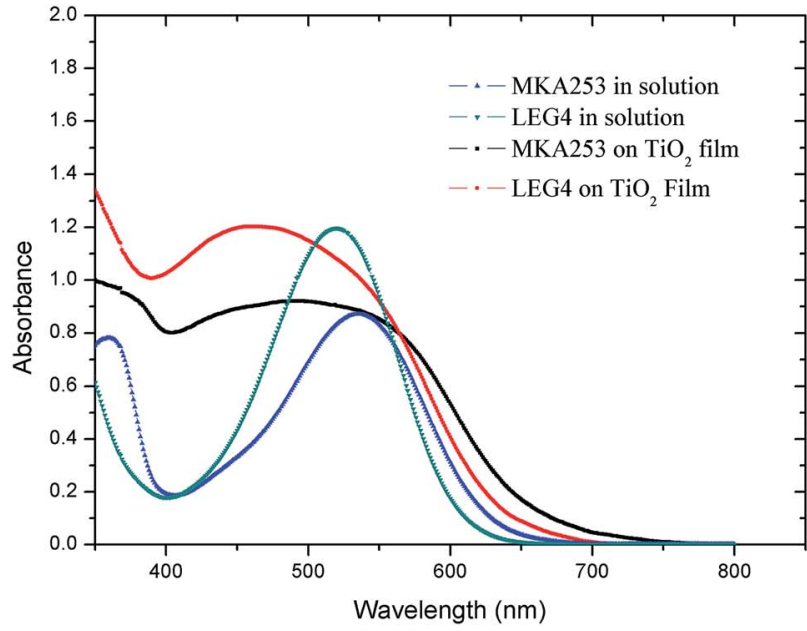

(a)

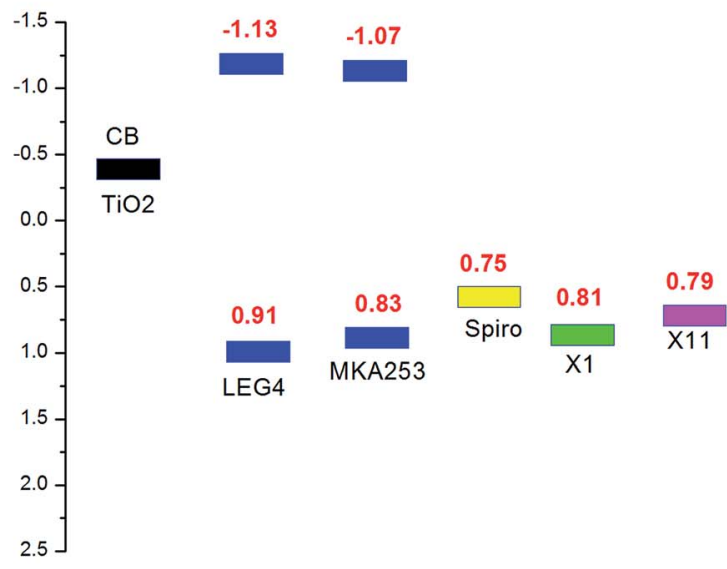

Potential (eV) vs SHE

Fig. 2 (a) UV-Vis absorption spectra of LEG4 and MKA253 in ethanol solution and on $\mathrm{TiO}_{2}$ film. (b) Energy alignment of the HOMO (and for the dyes LUMO) energy levels of the dyes and HTMs on the $\mathrm{TiO}_{2}$ film studied in this work.

HTM should be above (more negative on the Standard Hydrogen Electrode, SHE, scale) that of the sensitizer. Fig. 2b shows the energy level alignment of materials used in this paper. The energies of the Spiro-OMeTAD and X1 HOMOs are taken from the previously published paper. ${ }^{43}$ The values of the band gap for the two dyes are estimated from the UV-Vis absorption curves. More details about the experimental methods can be found in the ESI. $\dagger$ The HOMO of MKA253 is slightly more negative (SHE scale) in comparison with the LEG4 dye, resulting in a smaller band gap. All HTMs display more negative energy HOMO levels (SHE scale) than the sensitizers, which is essential for the dye regeneration procedure and the ability to work as an HTM. However, the HOMO of MKA253 is much closer to that of X1 and X11, indicating a smaller energy driving force. Furthermore, the Spiro-OMeTAD displays a less negative HOMO level as compared to X1 and X11, indicating a higher driving force for the dye regeneration process.

\subsection{Photovoltaic properties of SsDSSCs}

The $J-V$ characteristics of the ssDSSC fabricated using the sensitizers (LEG4 and MKA253) and HTMs (Spiro-OMeTAD, X1, and X11) studied at 1 sun illumination under standard global AM 1.5G conditions are shown in Fig. 3, with the corresponding photovoltaic parameters summarized in Table 1. For devices based on LEG4 and Spiro-OMeTAD, a high open-circuit potential $V_{\mathrm{oc}}$ of $935 \mathrm{mV}$ and a short-circuit current $J_{\mathrm{sc}}$ of $8.8 \mathrm{~mA} \mathrm{~cm}^{-2}$ were recorded, yielding a power conversion efficiency (PCE) of $5.2 \%$. The performance of devices containing LEG4 in combination with X1 or X11 as hole-transport materials showed $V_{\mathrm{oc}}, J_{\mathrm{sc}}$ and FF values of 720 and $655 \mathrm{mV}, 8.8$ and $8.2 \mathrm{~mA} \mathrm{~cm}^{-2}$, and 0.67 and 0.55 , yielding PCEs of $4.3 \%$ and $3.0 \%$, respectively. The devices containing the MKA253 dye and Spiro-OMeTAD showed an excellent efficiency of $6.1 \%$, which can be attributed to the high current of $12.4 \mathrm{~mA} \mathrm{~cm}{ }^{-2}$. The performance of cells containing X1 as the HTM is quite similar to that of cells containing $\mathrm{X} 11$. The cells based on X1 showed a $J_{\mathrm{sc}}$ of $5.8 \mathrm{~mA} \mathrm{~cm}{ }^{-2}$, a $V_{\mathrm{oc}}$ of $680 \mathrm{mV}$ and a PCE of $2.3 \%$, while the corresponding devices containing X11 showed a $V_{\mathrm{oc}}$ of $580 \mathrm{mV}$ and a $J_{\mathrm{sc}}$ of $4.7 \mathrm{~mA} \mathrm{~cm}{ }^{-2}$, resulting in a lower PCE, $1.7 \%$.

The devices based on Spiro-OMeTAD displayed the highest $V_{\text {oc }}(935 \mathrm{mV})$ in combination with the LEG4 dye, and the highest $J_{\text {sc }}(12.4 \mathrm{~mA})$ in combination with the MKA253 dye. For the same sensitizer, the $V_{\mathrm{oc}}$ of the solar cell devices decreased in the order Spiro-OMeTAD $>$ X1 $>$ X11. Furthermore, the $J_{\text {sc }}$ remained very similar for the devices based on LEG4 in combination with the different HTMs. In contrast, for MKA253, the device $J_{\text {sc }}$ dropped dramatically following the order Spiro-OMeTAD $>$ X1 $>$ X11.

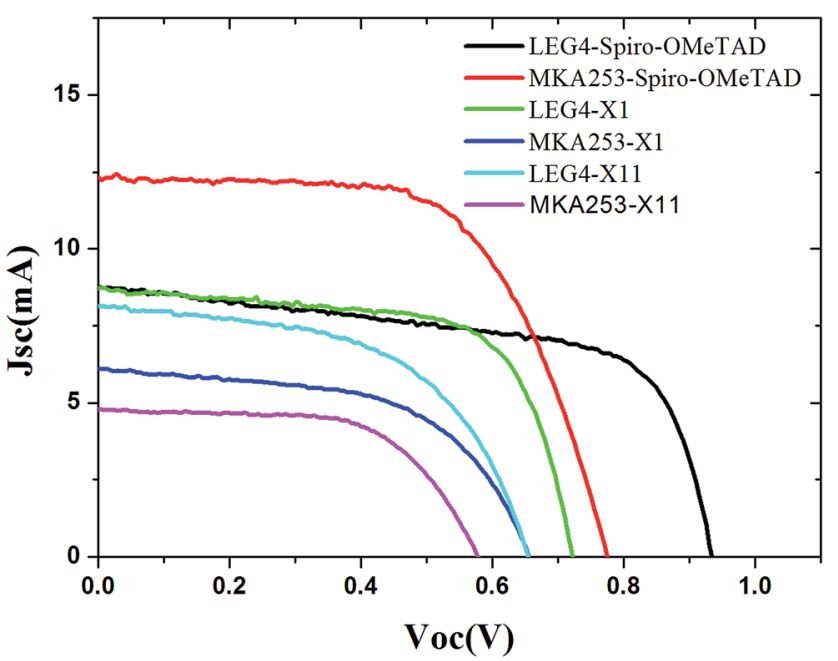

Fig. $3 \mathrm{~J}-V$ curves of the solid-state dye-sensitized solar cells based on different dyes and hole-transport materials. 
Table 1 Photovoltaic parameters of devices based on different sensitizers and hole-transport materials studied at a light intensity of $100 \mathrm{~mW} \mathrm{~cm}^{-2}$ (AM 1.5G)

\begin{tabular}{lclll}
\hline & $J_{\mathrm{sc}}\left[\mathrm{mA} \mathrm{cm}^{-2}\right]$ & $V_{\mathrm{oc}}[\mathrm{mV}]$ & $\mathrm{FF}$ & PEC \\
\hline LEG4/Spiro-OMeTAD & 8.8 & 935 & 0.63 & $5.2 \%$ \\
LEG4/X1 & 8.8 & 720 & 0.67 & $4.3 \%$ \\
LEG/X11 & 8.2 & 655 & 0.55 & $3.0 \%$ \\
MKA253/Spiro-OMeTAD & 12.4 & 780 & 0.63 & $6.1 \%$ \\
MKA253/X1 & 5.8 & 680 & 0.58 & $2.3 \%$ \\
MKA253/X11 & 4.7 & 580 & 0.62 & $1.7 \%$ \\
\hline
\end{tabular}

Therefore, the performance for devices based on MAK253 in combination with $\mathrm{X} 1$ and $\mathrm{X} 11$ was considerably much poorer than that of the Spiro-OMeTAD based devices.

\subsection{Incident photon-to-current conversion efficiency}

The higher $J_{\mathrm{sc}}$ values recorded for devices containing MKA253 in combination with Spiro-OMeTAD arise from the better lightharvesting ability of the dyes, which is evident in the incidentphoton-to-current conversion efficiency (IPCE spectra). The IPCE data are in good agreement with the results shown in Table 1. For ssDSSCs containing Spiro-OMeTAD as the HTM, the combination with MKA253 shows a much broader absorption range and the highest maximum monochromatic efficiency (76\% at $460 \mathrm{~nm}$ ), as compared to that of devices containing LEG4 (Fig. 4). According to Fig. 2a, the MKA253 and LEG4 dyes adsorbed onto the $\mathrm{TiO}_{2}$ film display an absorption edge at 730 $\mathrm{nm}$ and $680 \mathrm{~nm}$, respectively. The better light-harvesting abilities of MK253 thus logically should lead to higher $J_{\text {sc }}$, potentially giving rise to a higher PCE. For devices based on the LEG4 dye, the IPCE curves for the different HTMs are similar, and thus the corresponding $J_{\mathrm{sc}}$ are quite similar. However, for devices based on the MKA253 dye, the IPCE spectra for devices based on X1 and X11 as HTMs are much lower than those based on the LEG4 dye, consequently resulting in lower $J_{\mathrm{sc}}$, in spite of the potentially superior light-harvesting abilities of MKA253.

There are many factors that can affect the resulting device current. One of those could be that the relative energy alignment of the dyes and the hole-transport materials do not favor the energy or the electron transfer, resulting in a less efficient dye regeneration process. In general, the driving force for dye regeneration mainly arises from the energy difference between the HOMO energy level of the dye and the HTM. From Fig. 1b, we can note that the HOMO energy level of X1 and X11 is much closer to that of MKA253, if compared with that of Spiro-OMeTAD. Therefore, the dye regeneration for MKA253 may not be sufficiently efficient in devices combining the dye with X1 and $\mathrm{X} 11$ as the HTM. This aspect will be discussed further below.

\subsection{Electron lifetime measurement}

Recombination loss of the injected photoelectrons is one of the key factors that affect the performance of ssDSSCs. A longer electron lifetime indicates a lower recombination loss rate of the photogenerated charges, typically observed in terms of a

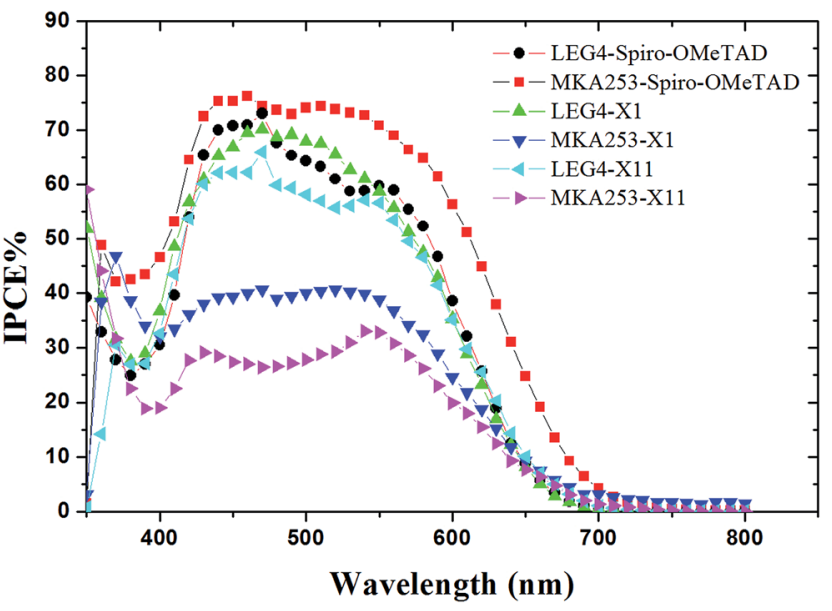

Fig. 4 IPCE spectra of the solid-state dye-sensitized solar cells based on different dyes and hole-transport materials.

higher $V_{\text {oc }}$ In Fig. 5, the electron lifetimes of different dyesensitized devices are plotted versus $V_{\text {oc }}$. The devices based on the LEG4 dye in combination with Spiro-OMeTAD showed the longest electron lifetime, while those based on MKA253 in combination with X11 presented the shortest electron lifetime. In general, the $V_{\text {oc }}$ of ssDSSCs is determined by the difference between the oxidation potential of the HTM and the quasiFermi level of $\mathrm{TiO}_{2}$. A shorter electron lifetime is expected to give a lower $V_{\text {oc }}$, since a higher degree of recombination losses would render a lower quasi-Fermi level. ${ }^{44} \mathrm{With}$ this in mind, the shorter electron lifetimes observed are in good agreement with the $V_{\text {oc }}$ data shown in Table 1. For devices containing SpiroOMeTAD as the HTM, the lifetime in combination with LEG4 is much longer than for those in combination with MKA253. The reason can be speculated to be associated with the less rigid donor part of LEG4 and possible effects on the recombination loss rate.

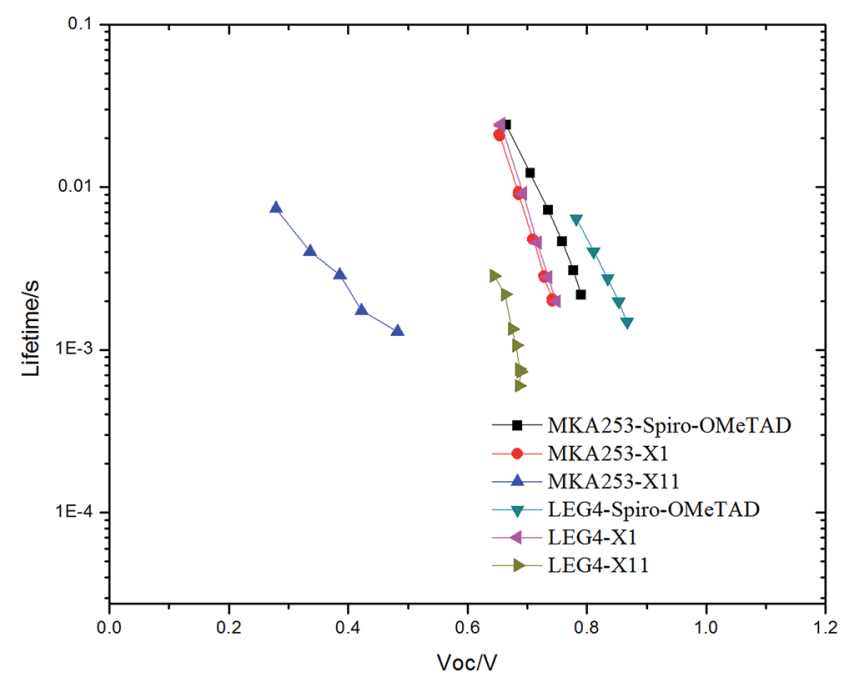

Fig. 5 Electron lifetime of different solid-state dye-sensitized solar cells versus the open-circuit potential. 

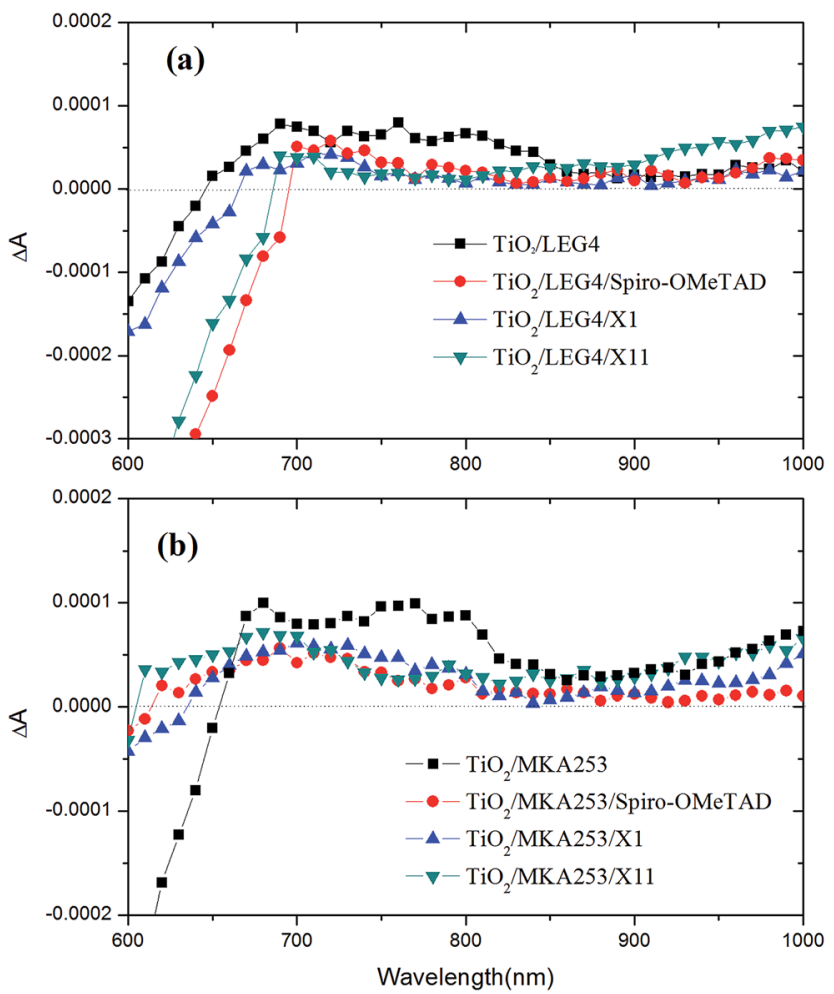

Fig. 6 PIA signals of different films based on LEG4 (a), and MKA253 (b).

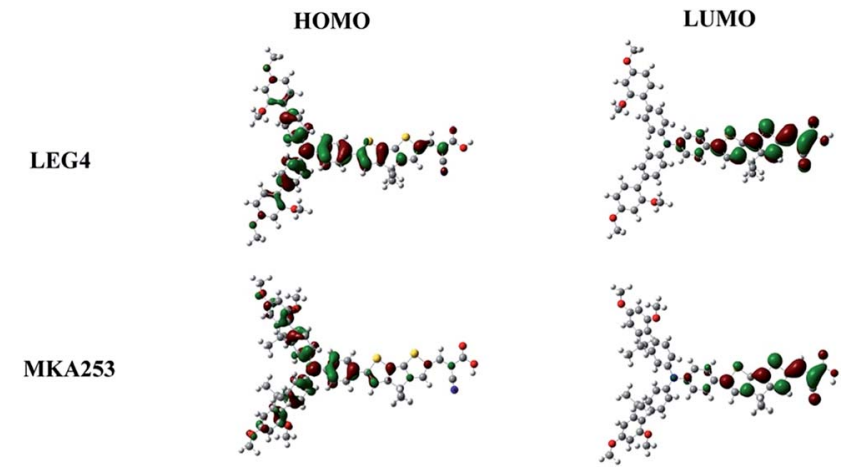

Fig. 7 Frontier orbitals of the dyes plotted at an isosurface value of 0.02 .

For the same sensitizer, similar trends can be noted: the electron lifetime for devices based on Spiro-OMeTAD is typically significantly longer than those based on X11 or X1. In spite of the fact that the more positive (SHE scale) HOMO energy level of X11 and X1 could result in a higher $V_{\text {oc }}$ (Fig. 2b), a better

Table 2 Re-organization energies calculated for sensitizers and holetransport materials

\begin{tabular}{llllll}
\hline & MKA253 & LEG4 & Spiro-OMeTAD & X1 & X11 \\
\hline $\begin{array}{l}\text { Re-organization } \\
\text { energy (meV) }\end{array}$ & 182 & 206 & 106 & 208 & 221 \\
& & & & &
\end{tabular}

pore-filling ability of the small-molecular HTMs may instead enhance the recombination loss process between injected electrons and the oxidized HTM. The present results indicate that there is a delicate balance between beneficial and detrimental effects expected from HTMs based on small molecules.

\subsection{Photo-induced absorption spectroscopy}

In order to study the regeneration process of the oxidized dye molecules by the hole transport materials, photo-induced absorption (PIA) spectroscopy was performed. Fig. 6a shows the absorption range between 700 and $800 \mathrm{~nm}$, which arises from the oxidized state of LEG4. After deposition of the HTM onto a $\mathrm{TiO}_{2} /$ LEG4 film, the decrease in intensity of absorption in this range is attributed to the dye regeneration process. Thus, it is clear that the absorption intensity at 700-800 nm decreased due to the dye regeneration in all cases. In general, the PIA curves of devices containing different HTMs did not show significant differences. However, between 700 and $750 \mathrm{~nm}$, the PIA spectra of the combinations $\mathrm{TiO}_{2} / \mathrm{LEG} 4 / \mathrm{X} 11$ and $\mathrm{TiO}_{2} / \mathrm{LEG} 4 / \mathrm{X} 1$ are more reduced as compared with that of $\mathrm{TiO}_{2} / \mathrm{LEG} 4 / \mathrm{Spiro}-$ OMeTAD, indicating faster dye regeneration of the former HTMs. From Fig. 2b, we can see that the driving force of dye regeneration for Spiro-OMeTAD is expected to be stronger than for the other two HTMs. This result may indicate yet another delicate balance in the devices; HTMs based on smaller molecules may be more easily infiltrated into the mesoporous $\mathrm{TiO}_{2}$ pores, leading to more efficient dye regeneration in spite of a lower thermodynamic driving force.

Fig. 6b shows the PIA spectra of MKA253-sensitized $\mathrm{TiO}_{2}$ films with and without HTM added. Here, we can note that the absorption between 650 and $850 \mathrm{~nm}$ arises from the oxidized state of the MKA253 dye molecules. For all three HTMs in combination with MKA253, the absorption intensity at 650$850 \mathrm{~nm}$ decreases, indicating an efficient dye regeneration process. Moreover, between 700 and $800 \mathrm{~nm}$, a slightly smaller effect was observed for the combinations with $\mathrm{X} 1$ and $\mathrm{X} 11$, as compared to that of Spiro-OMeTAD. Therefore, the MKA253/ Spiro-OMeTAD appears to show the fastest dye regeneration process. The reason could be attributed to the extremely low driving force of dye regeneration in the MKA253/X1 and MKA253/X11 systems. As seen in Fig. 2b, the very similar HOMO energy levels of X1 and X11 with respect to that of MKA253 may restrict the driving force for the dye regeneration. Therefore, the energy driving force is a vital factor to consider when searching for new HTMs for solar cells containing the MKA253 dye.

\subsection{Theoretical calculations}

In order to gain insight into the electronic and optical properties of the investigated dyes, DFT/TDDFT calculations were performed. Details of the calculation are given in the ESI. $\dagger$ The geometrically optimized dye molecules and their frontier orbitals are shown in Fig. 7. The dyes LEG4 and MKA253 display the typical HOMO-LUMO pattern of the family of D- $\pi-\mathrm{A}$ dyes, where the LUMO is mainly localized on the acceptor moiety and the HOMO is mainly localized on the donor and bridge part of the molecules. From the TDDFT calculations, the lowest 
Table 3 Conductivity of the hole-transport materials

\begin{tabular}{llll}
\hline & $\begin{array}{l}\text { Spiro-OMeTAD } \\
(30 \mathrm{mM})\end{array}$ & $\mathrm{X} 1(60 \mathrm{mM})$ & $\mathrm{X} 11(60 \mathrm{mM})$ \\
\hline Conductivity $\left(\mathrm{S} \mathrm{cm}^{-1}\right)$ & $1.37 \times 10^{-4}$ & $0.53 \times 10^{-4}$ & $0.42 \times 10^{-4}$
\end{tabular}

transition energies for protonated (deprotonated) LEG4 and MKA253 in the formal gas phase are 493 (437) nm and 588 (496) $\mathrm{nm}$, respectively, which are in good agreement with the experimentally observed UV-Vis absorption maxima. Furthermore, calculation results reproduced the absorption maximum trend, showing a slight red-shift going from LEG4 to MKA253.

The hole-transport rate between the dye molecules and the hole-transport materials can be one of the most important factors affecting the performance of the ssDSSCs. Non-adiabatic Marcus theory is used to estimate the charge-transfer rate ${ }^{45} M$ :

$$
M=\frac{2 \pi}{\hbar} \frac{|g|^{2}}{\sqrt{4 \pi \lambda k_{\mathrm{B}} T}} \mathrm{e}^{-\frac{\left(\Delta G_{0}+\lambda\right)^{2}}{4 k_{\mathrm{B}} T}},
$$

where $g$ describes the electronic coupling, $\Delta G_{0}$ is the difference in free energy between the equilibrium states of the products and reactants, and $\lambda$ is the re-organization energy. According to the Marcus theory, the re-organization energy is an important factor determining the hole-transport rate. Here, we calculated the re-organization energy of the dye and the HTM used in this work (Table 2). It is notable that the re-organization energy of the MKA253 dye is smaller than that of LEG4. Therefore, the hole after excitation and electron injection into the $\mathrm{TiO}_{2}$ substrate can be more readily transported through MKA253 dye multiple layers, indicating the regeneration process by the HTM to be facilitated. The lower re-organization energy observed could explain the high $J_{\mathrm{sc}}$ 's observed for the MKA253/SpiroOMeTAD-based solar cells.

For solid-state dye-sensitized solar cells, the hole-hopping process between the molecules constituting the materials also must affect the overall performance. From the calculation, the re-organization energy of Spiro-OMeTAD can be noted to be much lower than for the other two materials, indicating better transport abilities (Table 2). The results from conductivity measurements also support this hypothesis. From the data in Table 3, the hole conductivity of Spiro-OMeTAD, X1 and X11 films are $1.37 \times 10^{-4} \mathrm{~S} \mathrm{~cm}^{-1}, 5.3 \times 10^{-5} \mathrm{~S} \mathrm{~cm}^{-1}$, and $4.2 \times$ $10^{-5} \mathrm{~S} \mathrm{~cm}^{-1}$, respectively. The high conductivity of Spiro-OMeTAD is expected to reduce the charge transport resistance in the ssDSSC devices thus improving the FF.

\section{Conclusion}

A new organic donor- $\pi$-acceptor dye, MKA253, has been investigated in sSDSSCs. Devices based on the new MKA253 dye in combination with Spiro-OMeTAD as a hole-transport material yield impressive short-circuit currents of up to $12.4 \mathrm{~mA}$ $\mathrm{cm}^{-2}$, and a resulting power conversion efficiency of $6.1 \%$. In comparison with the LEG4 dye, the MKA253 dye shows a broader absorption range and higher IPCE values from the resulting SSDSSC devices. Calculation studies show that the reorganization energy of the MKA253 dye is much lower than that of the LEG4 dye. The lower re-organization energy may favor the hole-hopping process between multi-layers of dyes and also between the dyes and an HTM, resulting in more efficient dye regeneration.

The compatibility of the specific combinations of HTMs and sensitizers is an essential factor to consider when designing new ssDSSCs. Hole-conductor materials based on small molecules have also been investigated in this paper. For the same HTM, the devices based on fluorene donor dyes show much shorter electron lifetimes, compared with ones based on the LEG4 dye. For the LEG4 dye, the small molecular size of the hole transport material shows similar efficiency of dye regeneration, in comparison with Spiro-OMeTAD. However, the smaller size enhances the recombination between the $\mathrm{TiO}_{2}$ film and HTM, resulting in shorter electron life-time. For the MKA253 dye, the combination with $\mathrm{X} 1$ and X11 indicates an inefficient dye regeneration process as a result of a low thermodynamic driving force. Therefore, energy level alignment is an essential factor to consider when designing highly efficient solid-state dye-sensitized solar cells.

\section{Acknowledgements}

The Swedish Research Council, the Swedish Energy Agency, the Chinese Scholarship Council (CSC) and Knut and Alice Wallenberg Foundation are gratefully acknowledged for their financial support.

\section{References}

1 B. O'Regan and M. Grätzel, Nature, 1991, 353, 737-740.

2 A. Hagfeldt and M. Grätzel, Acc. Chem. Res., 2000, 33, 269277.

3 A. Hagfeldt, G. Boschloo, L. Sun, L. Kloo and H. Pettersson, Chem. Rev., 2010, 110, 6595-6663.

4 A. Yella, H.-W. Lee, H. N. Tsao, C. Yi, A. K. Chandiran, M. K. Nazeeruddin, E. W.-G. Diau, C.-Y. Yeh, S. M. Zakeeruddin and M. Grätzel, Science, 2011, 334, 629634.

5 Q. Yu, Y. Wang, Z. Yi, N. Zu, J. Zhang, M. Zhang and P. Wang, ACS Nano, 2010, 4, 6032-6038.

6 L. Alibabaei, J. H. Kim, M. Wang, N. Pootrakulchote, J. Teuscher, D. Di Censo, R. Humphry-Baker, J. E. Moser, Y. J. Yu, K. Y. Kay, S. M. Zakeeruddin and M. Grätzel, Energy Environ. Sci., 2010, 3, 1757-1764.

7 S. Haid, M. Marszalek, A. Mishra, M. Wielopolski, J. Teuscher, J.-E. Moser, R. Humphry-Baker, S. M. Zakeeruddin, M. Grätzel and P. Bäuerle, Adv. Funct. Mater., 2012, 22, 1291-1302.

8 S. Mathew, A. Yella, P. Gao, R. Humphry-Baker, F. E. CurchodBasile, N. Ashari-Astani, I. Tavernelli, U. Rothlisberger, K. NazeeruddinMd and M. Grätzel, Nat. Chem., 2014, 6, 242-247.

9 L. Bin, W. Liduo, K. Bonan, W. Peng and Q. Yong, Sol. Energy Mater. Sol. Cells, 2006, 90, 549-573. 
10 U. Bach, D. Lupo, P. Comte, J. E. Moser, F. Weissortel, J. Salbeck, H. Spreitzer and M. Grätzel, Nature, 1998, 395, 583-585.

11 N. Cai, S.-J. Moon, L. Cevey-Ha, T. Moehl, R. HumphryBaker, P. Wang, S. M. Zakeeruddin and M. Grätzel, Nano Lett., 2011, 11, 1452-1456.

12 J. Burschka, A. Dualeh, F. Kessler, E. Baranoff, N.-L. L. CeveyHa, C. Yi, M. K. Nazeeruddin and M. Grätzel, J. Am. Chem. Soc., 2011, 133, 18042-18045.

13 I. Chung, B. Lee, J. He, R. P. Chang and M. G. Kanatzidis, Nature, 2012, 485, 486-489.

14 J. Burschka, N. Pellet, S.-J. J. Moon, R. Humphry-Baker, P. Gao, M. K. Nazeeruddin and M. Grätzel, Nature, 2013, 499, 316-319.

15 H.-S. S. Kim, C.-R. R. Lee, J.-H. H. Im, K.-B. B. Lee, T. Moehl, A. Marchioro, S.-J. J. Moon, R. Humphry-Baker, J.-H. H. Yum, J. E. Moser, M. Grätzel and N.-G. G. Park, Sci. Rep., 2012, 2, 591.

16 N. J. Jeon, J. H. Noh, Y. C. Kim, W. S. Yang, S. Ryu and S. I. Seok, Nat. Mater., 2014, 897-903, DOI: 10.1038/ nmat4014.

17 M. Wang, J. Liu, N.-L. Cevey-Ha, S.-J. Moon, P. Liska, R. Humphry-Baker, J.-E. Moser, C. Grätzel, P. Wang, S. M. Zakeeruddin and M. Grätzel, Nano Today, 2010, 5, 169-174.

18 J. S. Henry, H.-B. Robin, C. Peter, C. Ilkay, M. Z. Shaik and G. Michael, Nanotechnology, 2008, 424003.

19 F. Fabregat-Santiago, J. Bisquert, L. Cevey, P. Chen, M. Wang, S. M. Zakeeruddin and M. Grätzel, J. Am. Chem. Soc., 2009, 131, 558-562.

20 J. S. Henry, P. Annamaria, I. Seigo, M. Hidetoshi and G. Michael, Adv. Funct. Mater., 2009, 1810-1818, DOI: 10.1002/adfm.200801751.

21 P. Chen, J. H. Yum, F. De Angelis, E. Mosconi, S. Fantacci, S.-J. J. Moon, R. H. Baker, J. Ko, M. K. Nazeeruddin and M. Grätzel, Nano Lett., 2009, 9, 2487-2492.

22 L. Kloo, Chem. Commun., 2013, 49, 6580-6583.

23 X. Jiang, K. Karl Martin, E. Gabrielsson, E. M. J. Johansson, M. Quintana, M. Karlsson, S. Licheng, G. Boschloo and H. Anders, Adv. Funct. Mater., 2011, 21, 29442952.

24 D. P. Hagberg, T. Edvinsson, T. Marinado, G. Boschloo, A. Hagfeldt and L. Sun, Chem. Commun., 2006, 2245-2247, DOI: 10.1039/b603002e.

25 Y. Jun-Ho, P. H. Daniel, M. Soo-Jin, K. Karl Martin, M. Tannia, S. Licheng, H. Anders, K. N. Mohammad and G. Michael, Angew. Chem., Int. Ed., 2008, 1576-1580, DOI: 10.1002/anie.200804719.

26 H. J. Snaith, A. J. Moule, C. Klein, K. Meerholz, R. H. Friend and M. Grätzel, Nano Lett., 2007, 7, 3372-3376.

27 W. Mingkui, X. Mingfei, S. Dong, L. Renzhi, G. Feifei, Z. Guangliang, Y. Zhihui, H.-B. Robin, W. Peng, M. Z. Shaik and G. Michael, Adv. Mater., 2008, 4460-4463, DOI: $10.1002 /$ adma.200801178.
28 T. Leijtens, I. K. K. Ding, T. Giovenzana, J. T. Bloking, M. D. McGehee and A. Sellinger, ACS Nano, 2012, 6, 14551462.

29 H. Wang, X. Zhang, F. Gong, G. Zhou and Z.-S. Wang, Adv. Mater., 2012, 24, 121-124.

30 J. E. Kroeze, N. Hirata, L. Schmidt-Mende, C. Orizu, S. D. Ogier, K. Carr, M. Grätzel and J. R. Durrant, Adv. Funct. Mater., 2006, 16, 1832-1838.

31 B.-w. Park, L. Yang, E. M. J. Johansson, N. Vlachopoulos, A. Chams, C. Perruchot, M. Jouini, G. Boschloo and A. Hagfeldt, J. Phys. Chem. C, 2013, 117, 22484-22491.

32 L. Yang, B. Xu, D. Bi, H. Tian, G. Boschloo, L. Sun, A. Hagfeldt and E. M. Johansson, J. Am. Chem. Soc., 2013, 135, 7378-7385.

33 J. K. Koh, J. Kim, B. Kim, J. H. Kim and E. Kim, Adv. Mater., 2011, 23, 1641-1646.

34 B. Xu, H. Tian, D. Bi, E. Gabrielsson, E. M. J. Johansson, G. Boschloo, A. Hagfeldt and L. Sun, J. Mater. Chem. A, 2013, 1, 14467-14470.

35 B. Xu, E. Sheibani, P. Liu, J. Zhang, H. Tian, N. Vlachopoulos, G. Boschloo, L. Kloo, A. Hagfeldt and L. Sun, Adv. Mater., 2014, 26, 6629-6634.

36 J. Zhang, L. Häggman, M. Jouini, A. Jarboui, G. Boschloo, N. Vlachopoulos and A. Hagfeldt, ChemPhysChem, 2014, 15, 1043-1047.

37 J. Zhang, L. Yang, Y. Shen, B.-W. Park, Y. Hao, E. M. J. Johansson, G. Boschloo, L. Kloo, E. Gabrielsson, S. Licheng, A. Jarboui, C. Perruchot, M. Jouini, N. Vlachopoulos and H. Anders, J. Phys. Chem. C, 2014, 118, 16591-16601.

38 Y. Aswani, H.-B. Robin, F. E. C. Basile, A. Negar Ashari, T. Joël, E. P. Lauren, M. Simon, E. M. Jacques, T. Ivano, R. Ursula, G. Michael, N. M. Khaja and F. Julien, Chem. Mater., 2013, 25, 2733-2739.

39 E. Gabrielsson, H. Ellis, S. Feldt, H. Tian, G. Boschloo, H. Anders and S. Licheng, Adv. Energy Mater., 2013, 3, 16471656.

40 G. Boschloo and A. Hagfeldt, Inorg. Chim. Acta, 2008, 361, 729-734.

41 M. Pastore, E. Mosconi, F. Angelis and M. Grätzel, J. Phys. Chem. C, 2010, 114, 7205-7212.

42 A. Dualeh, F. D. Angelis, S. Fantacci, T. Moehl, C. Yi, F. Kessler, E. Baranoff, K. N. Mohammad and G. Michael, J. Phys. Chem. C, 2012, 116, 15721578.

43 B. Xu, H. Tian, L. Lin, D. Qian, H. Chen, J. Zhang, N. Vlachopoulos, G. Boschloo, Y. Luo, F. Zhang, A. Hagfeldt and L. Sun, Adv. Energy Mater., 2014, 1401185.

44 P. Chen, J. H. Yum, F. D. Angelis, E. Mosconi, S. Fantacci, S.-J. Moon, R. H. Baker, J. Ko, M. K. Nazeeruddin and M. Grätzel, Nano Lett., 2009, 9, 2487-2492.

45 R. A. Marcus and N. Sutin, Biochim. Biophys. Acta, 1985, 811, 265-322. 